\title{
Whose Advice is Credible? Claiming Lay Expertise in a Covid-19 Online Community
}

\author{
Larry $\mathrm{Au}^{1}{ }^{\mathbb{D}} \cdot$ Gil Eyal $^{1}$
}

Accepted: 1 June 2021/Published online: 3 November 2021

(C) The Author(s), under exclusive licence to Springer Science+Business Media, LLC, part of Springer Nature 2021

\begin{abstract}
During the initial months of the Covid-19 pandemic, credentialed experts-scientists, doctors, public health experts, and policymakers - as well as members of the public and patients faced radical uncertainty. Knowledge about how Covid-19 was spread, how best to diagnose the disease, and how to treat infected patients was scant and contested. Despite this radical uncertainty, however, certain users of Covid-19 Together, a large online community for those who have contracted Covid-19, were able to dispense advice to one another that was seen as credible and trustworthy. Relying on Goffman's dramaturgical theory of social interaction, we highlight the performative dimension of claims to lay expertise to show how credibility is accrued under conditions of radical uncertainty. Drawing on four months of data from the forum, we show how credible performances of lay expertise necessitated the entangling of expert discourse with illness experience, creating a hybrid interlanguage. A credible performance of lay expertise in this setting was characterized by users' ability to switch freely between personal and scientific registers, finding and creating resonances between the two. To become a credible lay expert on this online community, users had to learn to ask questions and demonstrate a willingness to engage with biomedical knowledge while carefully generalizing their personal experience.
\end{abstract}

Keywords Uncertainty $\cdot$ Credibility $\cdot$ Lay expertise $\cdot$ Illness experience $\cdot$ Covid-19

Larry Au

larry.au@columbia.edu

Gil Eyal

ge2027@columbia.edu

1 Department of Sociology, Columbia University, 501 Knox Hall, 606 W 122nd Street,

New York, NY 10027, USA 


\section{Introduction}

The initial months of the Covid-19 crisis in the United States were characterized by radical uncertainty about the outbreak, coupled with a tendency to doubt and mistrust public health experts. As scientists, doctors, and policymakers struggled to develop effective strategies to contain disease spread, develop diagnostic criteria, and identify treatment options for the disease, their credibility suffered. In this article, we seek to throw some light on the intricate relations between uncertainty and credibility by examining conversations on Covid-19 Together, an online community started in the very first months of the pandemic in the US, where those who tested positive for Covid-19, were presumed positive, or had family members who had Covid-19, share their experiences. We examine whose advice is deemed credible on this online forum and what determines this. As members of this forum grapple with existential uncertainty, feeling that their very lives are in danger, one might have expected them to endow authoritative experts-like Anthony Fauci or their doctor-and biomedical science with a great deal of credibility. Conversely, one might have thought that uncertainty would lead them to doubt all official experts, anoint their would-be-experts, and see as credible only fellow sufferers. Yet, we find that neither is quite the case. We will show that credible advice on Covid-19 Together was characterized by linking shared illness experience with resonant biomedical knowledge through a hybrid interlanguage. Attempts to provide advice by merely asserting what "the science" says or by relying purely on personal experience were deemed not as credible.

This finding accords with the overall balance of the research on "lay expertise" and patient communities. Much of this research focused on situations of heightened uncertainty, either because the disease in question was new, like HIV/AIDS, or because it was a contested or an "orphan" illness that the medical establishment has ignored. Sociologists have shown that in such situations, the uncertainty surrounding disease and illness created an opening for patients to turn themselves into credible "lay experts." ACT-UP activists, for example, turned themselves into lay experts and gained credibility by learning the language and protocols of scientific research, but they could only do so because they acted as representatives of an affected group whose illness experiences they shared (Epstein 1995). Similarly, studies of "orphan illnesses" questioned the "deficit model" of the public's understanding of science (Kerr et al. 1998), and showed how illness experiences can be combined with self-education to credibly contribute to expert understandings of health and illness (Prior 2003). Online patient communities-forums, Wikis, blogs, Facebook groups - in particular have become a popular setting for research on lay expertise. Studies have shown how online communities serve as sites of shared commiseration of illness experience, focusing on the subjective experiences of illness, medical neglect or maltreatment, and on coping strategies for managing life with the disease (e.g. Barker 2008; Kempner and Bailey 2019; Petersen et al. 2020; Pierret 2003; Radin 2006; Ross et al. 2018). 
Note, however, that we spoke above about credibility as something that forum members "endow" claims with. Credibility is a relationship between performer and audience. It is built on stage in real time, and it is highly dependent on temporal variables - sequence, speed, interval, duration-to achieve resonance with the audience. We seek to add to the literature on lay expertise and patient communities by drawing on Goffman's (1959) dramaturgical theory of social interaction and focusing on the performative aspect of expertise and advice-giving (Carr 2010; Hilgartner 2000). Attention to this performative aspect can shed additional light on why, in situations of radical uncertainty, credibility depends on a resonant interlanguage combining biomedical knowledge with shared personal experiences. While the literature on lay expertise has convincingly demonstrated that biomedical knowledge can be transformed-willingly or not-by incorporating the shared experiences of lay patients, it is important to recognize that in situations of heightened uncertainty this sharing of experiences, "illness identity," is not a given. Patients do not know yet whether they are suffering from "the same" condition. This is particularly true for complex syndromes where there are multiple symptoms and potential diagnoses, requiring patients to learn to recognize that they are "similar-but-different" to each other (Barker 2009, p. 64). In such situations, patients would not automatically endow with credibility one who speaks to them purely as a fellow sufferer. Hence, the obverse is no less important: biomedical knowledge can be a crucial resource that allows patients to recognize that their illness experiences are similar, valid, and not just "in their heads." Credible performances are thus resonant also because they create their own audience. They need to persuade audience members of the similarity and objectivity of their situation for the constituted audience to reciprocate by endowing the performance with subjective credibility. Lay expertise in a situation of radical uncertainty is thus deemed credible if claimants can create a convincing hybrid interlanguage. This is not, however, a recipe that one can follow at their leisure. It is a performance that demands attention to temporality. We will show that there was a certain sequence by which the credibility of advice-giving was constructed. Users could not immediately present themselves as "lay experts." They had to begin by asking questions, establishing in this way their bona fides status as lay patients. They followed this up, however, by engaging with biomedical knowledge, and carefully, qualifiedly, emphasizing what resonated with their personal experience.

In this study, we ask: (1) What characterizes credible as against non-credible advice on Covid-19 Together? and (2) What is the sequence by which the ability to provide credible advice is acquired on this online community? We begin with a review of the literature on lay expertise, credibility, and uncertainty. Then, we describe the data and the mixed qualitative and computational methods used to trace discussions on Covid-19 Together. We then detail our findings and end with concluding thoughts on how this study of lay expertise may contribute to other discussions of the public's role in shaping scientific and biomedical knowledge. 


\section{Credibility, Uncertainty, and Lay Expertise}

To give advice on Covid-19 Together is a performance, the credibility of which we define along the lines of Goffman's (1959) dramaturgical theory of social interaction: by the audience's response. As Goffman states: "There are many statuses in which membership is not subject to formal ratification... where standards of competence are not objective, and where bona fide practitioners are not collectively organized to protect their mandate, an individual may style himself an expert and be penalized by nothing stronger than sniggers" (Goffman 1959, p. 39). To give advice on Covid-19 Together is to "style oneself" as some sort of expert. The credibility of the performance can be judged by the audience's applause. As Goffman intimates, the performance of expertise here is different from that of credentialed experts. In Hilgartner's (2000) analysis of scientific advisory boards credentialed experts engage in active stage management to give off an impression of objectivity. This is not the impression that advice-givers on Covid-19 Together strive to create and why the concept of "lay expertise" has some, albeit limited, usefulness. ${ }^{1}$ The role of lay expert fits Goffman's description of statuses "not subject to formal ratification," open to a wide range of claimants who do not claim objectivity. On the contrary, at times they claim some form of subjectivity to speak authoritatively based on their experiences. The credibility of such performance is evaluated differently by the audience compared with the credibility of credentialed experts. Credible performance of lay expertise, by giving advice on Covid-19 Together, paradoxically also requires performance of (in)expertise (Carr Forthcoming), distancing oneself from speaking as a credentialed expert. This can be to avoid the opprobrium incurred by those trying to pass themselves off as who they are not. As Goffman (1959) argues: "It is felt to be an inexcusable crime against communication to impersonate someone of sacred status, such as a doctor" (39). But it can be-as we argue-because under conditions of radical uncertainty, when there is a tendency to mistrust experts, presenting oneself as "not an expert" is a useful strategy to bypass the crisis of expertise that would

\footnotetext{
1 We use "lay expertise" without engaging with whether it is an oxymoron (Collins and Evans 2007; Epstein 2021). We note that there is dissatisfaction with the term "lay expertise" amongst researchers. As Evans and Plows (2007) write, "'Scientist' is too narrow a category, while 'public', even when pluralized as 'publics', conflates groups that are quite distinct" (828). The question, of course, is what constitutes "specialist expertise" and how to distinguish between these groups. The categories of interactional expertise and contributory expertise attempt to do this (Collins and Evans 2007). In this model, however, different types of claims to expertise are kept apart and are ranked, with contributory expertise being "more" than interactional expertise (Selinger and Mix 2004). Researchers uneasy about this hierarchy developed neighboring concepts such as expert patients (Pols 2014), embodied health movements (Brown et al. 2004; Nelson 2011), lay epidemiology (Bloor 2000; Brown 2007; Davison et al. 1991; Jauho 2017; Russell and Kelly 2011), lay pharmacovigilance (Barker 2019), collective self-experimentation (Kempner and Bailey 2019), self-tracking and self-expertise (Heyen 2020), communities of practice (Akrich 2010), and everyday fringe medicine (Vuolanto et al. 2020). The question for us is pragmatic: can the concept do useful analytical work? We think it does, especially when the juxtaposition of opposites in one concept does not stand for a stable position or role but for the movement back and forth between two unstable poles. This is the thrust of our empirical analysis.
} 
shut down lines of communication when the contested identity of the credentialed expert is invoked (Eyal 2019). ${ }^{2}$

Sociologists have asked how lay experts gain credibility. Some, like Epstein (1995), emphasized that laypeople become credible lay experts by learning the language of credentialed experts and acquiring their knowledge. Lay members of the public teach themselves scientific concepts and methods, how to read scientific articles, and eventually can stake a position and intervene in scientific controversies. While they may not become contributors to scientific research, they acquire a form of "interactional expertise" and thus gain "a seat at the table" (Collins and Evans 2009). Others have focused on laypeople's struggles to gain acceptance and credibility for their own experiential and embodied knowledge. The Cambrian sheep farmers studied by Wynne (1996) did not attempt to learn nuclear physics, but they claimed to be credible experts by virtue of long years of raising sheep next to the Sellafield nuclear power station. Similarly, patients suffering from contested illnesses (Barker 2008), where medical experts have differing opinions on the diagnosis and treatment of specific syndromes, have claimed that their own illness experiences constitute alternative and credible bases of expertise. Patients come with embodied health knowledge that challenges or adds to medical professionals' expertise, who lack understanding of how the illness affects the patient on a day-to-day basis (Brown et al. 2004).

The distinction made in the previous paragraph is ideal typical. Most sociologists have paid attention to both sources of credibility-learning the language of experts and claiming relevance for experiential knowledge - as well as to their interrelations. Indeed, many have demonstrated how learning to speak the language of experts has allowed laypeople to craft an "intermediary discourse" (Rabeharisoa and Callon 2004), in which credibility accrues to experiential knowledge, and by the same token, embodied knowledge can then be converted into scientific knowledge through codification, quantification, and testing. For example, websites like PatientsLikeMe have moved from being a forum for shared commiseration, into a platform where researchers partner with patient groups to conduct research (Kempner and Bailey 2019). The Quantified Self Movement can be seen to be doing something similar, quantifying subjective feelings into a quasi-objective metric (Heyen 2020). This is particularly useful when lay experts venture out from patient communitiesarmed with scientific evidence-to interact with policymakers and credentialed experts. What sociologists perhaps did not yet ask is how does one perform in situ this combination of claims.

One thing, however, that sociologists demonstrated is that uncertainty is not simply a predicament, but a resource for would-be experts. Where there is uncertainty amongst credentialed experts-or when available scientific knowledge loses its power to convince its audience that it can solve a patient's medical complaintsthe claims from experience enjoy more credibility. To some extent, this mirrors the relations between uncertainty and credibility in medicine generally. Medical

\footnotetext{
${ }^{2}$ Carr (Forthcoming) finds that Motivational Interviewing therapists engage in a similar strategy of proclaiming "(in)expertise" to win the confidence and cooperation of potentially skeptical clients.
} 
professional socialization teaches student physicians to recognize the limits of scientific knowledge and to manage uncertainty in their day-to-day roles (Fox 1957; Light 1979). Diagnosis, in particular, requires the physician to collapse a wider range of factors to arrive at a decision (Brown 1995; Jutel 2009). Clinical expertise thus consists of the honed ability to arrive at good decisions in situations of uncertainty (Dreyfus and Dreyfus 2005), and despite attempts at standardization, the management of uncertainty continues to be part of the everyday roles of physicians (Timmermans and Angell 2001). Affected communities, however, often offer an alternative program before there is certainty (Rabeharisoa and Callon 2004). In situations involving illness where scientific knowledge is lacking, such as with chronic fatigue syndrome (Barker 2008) and migraines (Kempner 2014), patient communities were able to use uncertainty as a resource that added to their credibility. This is evident in the struggle over diagnosis of contested illnesses because the ability of clinical expertise to use uncertainty as a resource is limited by bureaucratic classifications used by hospitals and insurers (Dumit 2006), while patient communities are not similarly bound. As patients challenge existing classifications, they cast doubt on the credibility of clinical expertise, and offer their expertise as an alternative.

These observations are relevant because of the lack of knowledge about the diagnosis, prognosis, and treatment of Covid-19. Moreover, the uncertainty is exacerbated by the pandemic's novelty, severity, duration, and global reach. The challenge in global health emergencies such as the Covid-19 pandemic is not only the need to make life-altering decisions when facing uncertainty, but also the urgency and speed needed in arriving at a course of action (Lakoff 2017). Instead of simply contending with medical uncertainty, credentialed experts also confronted global health uncertainty and public health uncertainty, with the lack of basic scientific knowledge about the disease and with the lack of knowledge over its transmission (Kelly et al. 2020). These areas of "undone science" (Frickel et al. 2009) and "strategic unknowns" (McGoey 2012) invite a wider range of experts to make claims. ${ }^{3}$ Scientific and public health knowledge about the disease that would otherwise be takenfor-granted becomes open to debate amongst credentialed experts. The struggle among credentialed experts constitutes both an opening and an obstacle for wouldbe lay experts. On the one hand, they can exploit the ensuing uncertainty to claim credibility. On the other hand, to establish the broader relevance of their experiential knowledge, to be able to share it with others, they need to link it with scientific facts. After all, when scientific facts circulate beyond the laboratory, these facts needed to be interpreted and defended rhetorically by scientists and their allies (Eyal 2019, p. 6; Latour 1987). Thus, the struggle among credentialed experts rendered the credibility of giving advice and performing expertise on Covid-19 Together vulnerable. Members not only defended their own illness experiences, but the scientific

\footnotetext{
3 Bibliometric analysis of Covid-19 scientific publications showed that most early publications came from East and Southeast Asian countries, showing the geographic distribution of knowledge (Chahrour et al. 2021). Most studies were also clinical and field based, rather than laboratory studies, but the sheer scale of scientific research is unprecedented, with over 48,000 articles mentioning Covid-19 published by the end of July 2020 (Doanvo et al. 2020).
} 
knowledge that they drew on to make sense of Covid-19. Through the forum, we trace the rhetorical tactics mounted by lay experts.

We find that in this situation of radical uncertainty, credible performances of lay expertise on Covid-19 Together required users to tack back-and-forth between the specialized language of credentialed experts (i.e. interactional expertise) and the subjective language of personal experience (i.e. embodied expertise). This is similar to the idea of "intermediary discourse" that is "neither purely technical nor purely strategic, which enables patients to go into the content of research without... losing sight of the goals" (Rabeharisoa and Callon 2004, p. 151), and "patient knowledge" or when "practical knowledge to translate knowledge from different sources and advices [patients] get into usable techniques" (Pols 2014, p. 78). The difference is that we emphasize the performance of this discourse in real time, and how aspects of performance impact its credibility. The concept of "intermediary discourse" is a snapshot in time, the culmination of multiple performances that established the credibility of its components. At the pandemic's onset, neither scientific knowledge nor personal experience about Covid-19 is well-established enough to convince the audience that a claim is credible. When contributors to the forum write in "pure" registers of either biomedical knowledge or personal experience, their advice is deemed less credible. Successful performances move rather freely between a personal register in which they describe their day-to-day, embodied illness experiences and a scientific register where the same experiences are analyzed using terms borrowed from biomedicine. Claims to lay expertise fashion resonances between previously de-contextualized biomedical knowledge with the messy reality of everyday life for patients, and vice-versa. We draw here on McDonnel, Bail, and Tavory's (2017, p. 2) discussion of pragmatism and the resonance of cultural objects: "a cultural object 'works' because it resonates_-but it also resonates because it works." This directs attention to the hybrid performative style of lay experts: scientific findings resonate with patients if lay experts explicate them in ways that correspond to their personal experience with Covid-19 and/or are useful in managing their illness. By the same token, personal experiences would resonate with other patients if the reporter is can link them with biomedical concepts, otherwise they run the risk of remaining "in one's head." Performances unfold in real time: To succeed they require attention to sequence and timing. One does not begin with scientific assertions. Often the gambit requires the construction of initial (in)expertise (e.g. "I'm not a doctor"). Learning to perform this hybrid interlanguage (Galison 2010), reflects a "metalinguistic awareness" which can become "a powerful institutional and political resource" in medical settings (Carr 2010, p. 225). When lay experts are consulted on patient advisory boards or organize into patient advocacy groups, this hybrid interlanguage can adapt to its new audience and be made intelligible to credentialed experts.

\section{Data and Methods}

The online community, Covid-19 Together, was created in mid-March. The forum is a part of a general-purpose social media site where anyone can start a new discussion board. As far as we can tell, the forum has no formal ties to any medical, 
scientific, or pharmaceutical organizations. ${ }^{4}$ Over four months until mid-July, it had over 24,000 users who contributed to the forum by posting. A core set of about 400 users contributed 50 or more posts during this period. The online community created more than 9,800 threads containing over 138,000 posts during the four months. Each post varied in length, ranging from pages of text to short sentences and snarky replies. The mean number of characters was 310 or about 60 words or two sentences. The median number of characters was 178 or about 35 words or a sentence. The number of comments posted per day on the forum ranged from about 750 to 1,250 comments per day. The number of comments posted picked up quickly from the forum's creation in mid-March as the forum gained a certain degree of "virality." There was a consistent level of contributions from the end of March to the end of our observation period in mid-July, reflecting the consistent engagement and the usefulness of the forum for patients. Unlike other Covid-19 related forums that share news articles and speculate on developments related to the pandemic, Covid-19 Together is focused on being "a space for folks who tested positive for Covid-19 to share your experiences, resources, and let off some steam." While no systematic comparison was conducted with other forums related to Covid-19, users on Covid-19 Together frequently commended other community members for their civility and collegiality, contrasted against the unruly and disruptive behavior that exist in other Covid-19 forums. The forum is moderated by a small team of users, who remove irrelevant posts and attempt to uphold community standards, guarding the forums against trolls. The moderators exerted significant influence on the types of claims that users could make on the forum. Nonetheless, despite the intent of moderators to exclude claims to credentialed expertise or the provision of "medical advice," we will show that users were able to make assertions about what could be learned from scientific and biomedical research. At the same time, the forum's moderators did not provoke too much ire or dissent from its users, signaling, perhaps, a degree of agreement among users about the implicit rules of judgement they employed. Moderation was also largely reserved for new threads rather than individual posts within threads, and the volume of posts-1,000 or so each day-typically was too much for the team of 10 moderators to review thoroughly. Using an API provided by the forum, these posts were downloaded for analysis. In addition to this, discussions on the forums were tracked in real time-as we received email and notifications for new notable threads. These impressions gained from real time observation during this period also

\footnotetext{
4 The selection of this forum conforms to Eysenbach and Till's (2001) insistence that online qualitative health research be done on "public" sites. The selected forum is considered more "public" than "private," as it is not password protected, not restricted to users, and is indexed on search engines. This is also a large user community, which indicates that posts on the forum are meant to be read by a wider community. While Eysenbach and Till (2001) insists that researchers should not "lurk" and that they should seek consent from forum members, Barker (2008) points out that this is unrealistic due to the number of members who are involved in online community with varying degrees of participation, as well as the fact that disclosing the presence of a researcher changes the ways in which users participate in the forum. We changed the name of the online community and gave pseudonyms to the users. Direct quotes taken from this website are altered with synonyms replacing key words, while preserving the meaning of these excerpts. This is not a guarantee of users' anonymity as their postings may still be revealed through online search.
} 
helped familiarize us with the wide range of conversations on the forum, as well as provided a sense of the temporality of posting — sequence and pace-that could be easily missed in a retrospective analysis.

Due to the quantity of text, we analyzed the data in two stages. First, we attempted to characterize the themes in the text to get a sense of what was being discussed by users on the forum. To achieve this first objective, we combined an abductive approach with assistive automated coding to analyze the posts on Atlas.ti (Deterding and Waters 2018; Tavory and Timmermans 2014). First, we produced a list of words and frequency and examined it for relevant keywords. Second, we developed a coding scheme, covering topics such as feelings (e.g., trust, uncertainty), sources of information (e.g., Fauci, Google), interactions with medicine and medical professionals (e.g., doctors, test), and controversies (e.g. masks, ibuprofen). In addition to these codes, symptoms (e.g., fever, shortness of breath) and place names (e.g., New York City, California) were coded as well. Third, we applied this coding scheme using the Auto Coding function, in which paragraphs containing the relevant keywords for each code were linked to it. Finally, we used the Code Co-Occurrence tool to locate discussions that touch on two different codes. For example, co-occurrence of codes for trust and science locates conversations about trust (or mistrust) of science. Additionally, computational text analysis was used to explore the data. Three broad topics of discussions were detected using topic modeling techniques: symptoms and course of illness, staying home and related emotions, and experiences with testing and doctors. The associated terms are reported in Table $1 .{ }^{5}$ In the first topic of symptoms of illness, the associated terms relate to symptoms such as shortness of breath, cough, fever, chest pains, loss of smell, headaches, and fatigue, as well as to the course of the illness (day, week, start, etc.). This is seen clearly in posts that painstakingly detail day-to-day changes of the patients' illness experiences, from onset to the months-long recovery of Long-Haulers. The second topic combines terms that describe the experience of isolating and staying home and the related emotional states. Because this topic likely refers also to steps users have taken to prevent catching Covid-19 or to their period of quarantine after suspected infection, it includes also terms related to prevention and recovery such as masks, vitamins, rest, eating well, and staying home as well as terms related to the stress of having the disease and isolating, such as anxiety and worry. The third topic seems to center on interactions at the medical system's access points (Giddens 1990), namely with testing and doctors. The topic includes terms such as test, positive, negative, blood, and result. There are also terms related to recovery, antibody tests, and immunity. This topic includes reports on difficulties that patients faced in getting medical professionals to take their symptoms seriously and patients' mistrust of testing results. This broad grouping of discussions corresponds with our qualitative understanding

\footnotetext{
5 The R tm package for topic modeling was used to perform a Latent Dirichlet Allocation (LDA) analysis of the text. Of the posts in the forum, those with over 100 characters or approximately 20 words were kept. This left 96,666 posts of the full set of 138,488 posts. The stop words were removed from the text and stemmed. Clusters ranged from two to five topics were used, and the decision to include three clusters was based on the ability of the topics to meaningfully reflect the themes that arose from qualitative readings of the text.
} 


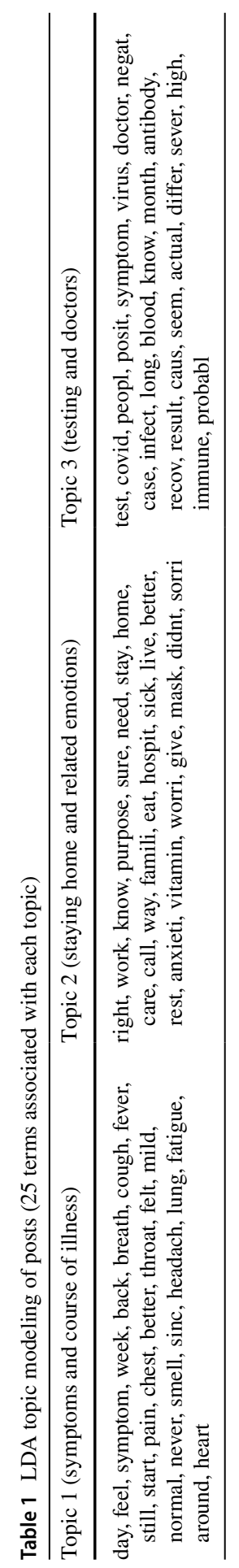


of the data, and the themes were relatively consistent during the four months of observation.

Second, after understanding the general themes under discussion, we attempted to answer the question we formulated earlier, namely how users perform credible lay expertise. Operationalizing credibility is a difficult task as rhetorical performances on the forum rely on conversational dynamics that are sequential and asynchronous, consist of links, images, and videos, and rely on colloquialisms, sarcasm, and technical terminologies. One way in which we tried to do this is by using the in-built voting function on Covid-19 Together, where posts that are deemed praiseworthy can be "liked" and those that are seen as unhelpful or off topic can be "disliked" by other users, resulting in a score that subtracts the number of dislikes from total likes. There was a considerable range in scores. The maximum score was 3,860 and the minimum was -104; the mean was 5 and the median was 2 . This measure was straightforward but has the distinct disadvantage that it can measure many other things apart from credibility, let alone lay expertise (e.g., popularity, a joke landing well). Hence, we selected a purposive sample of the top 1,000 and bottom 1,000 scoring posts and analyzed them qualitatively and comparatively, looking for posts that involved giving advice and providing information (hence staking at least a minimal claim to expertise), and searching for characteristics that could have made this instance of advice-giving more or less credible. ${ }^{6}$ We developed a coding scheme inductively to capture the various explanations for posts deemed most credible and those that were seen as the least credible. Furthermore, to trace the process of becoming a lay expert, we examined the top 100 active users' postings on the forum by post counts. The top 100 users contributed over 27,000 posts. We traced the trajectory of users by skimming these posts, with attention paid to high and low scoring posts at the beginning, middle, and end of a user's posting history. This enabled us to observe the temporal dynamics by which credibility is accrued or lost, and how this may impact over time the tone, style, and topics raised by the user. A description of this trajectory was recorded for each top user. It is important to restate here that the number of posts a user contributes and the number of likes that a post receives are only proxies for a credible performance of lay expertise. Some users post a lot on the forum but never seem to be seen as by other users as credible information providers. Some posts receive significant attention, but for reasons other than providing credible information or advice.

There are more limits to using this data. First, it would be unwise to attempt to glean demographic information from semi-anonymous profiles. Certainly, the impact of Covid-19 is different along racial, national, class, disability, and gender groups. However, it does seem that most of the contributors are located in the United States given the frequency of place-name mentions. Second, reported attitudes may not reliably reflect actual behavior, but this analysis aims to capture discourse. Third, emojis and other images inserted into the text were not captured and

\footnotetext{
${ }^{6}$ Users and moderators were also able to delete or remove posts. Of the top 1,000 posts, 66 were no longer available. Of the bottom 1,000 posts, 266 were no longer available. Likewise, deleted and removed posts from the top 100 users were also not available.
} 
analyzed systematically. Fourth, this data only tracks discussions amongst Covid-19 patients—omitted here are how medical practitioners perceived patients. Nonetheless, this data is still useful for studying how users performed lay expertise and won credibility during the Covid-19 crisis.

\section{Findings}

Before we detail our findings, we should note an important aspect of the context in which such performance of lay expertise—specifically, dispensing advice-was to be received. Organizers of this forum explicitly frowned upon users providing medical advice, referring to medical or scientific knowledge, without personal experience of the matter. Cognizant of what takes place in other forums, organizers and users were wary of posters pretending to be credentialed experts. This is seen clearly in the rules of the online community:

- "Please be kind. This is a stressful period. Avoid being rude and personal attacks on each other. No trolling."

- "Do not provide medical advice. Even though you may discuss medicine, remember that we are not medical experts. Seek help from your doctor if you are concerned about your health."

- "Think before posting news items that may alarm each other. We don't want to create further anxiety."

- "Write from your personal experience. We want to learn firsthand about your experience with Covid-19."

The rule of no medical advice was not just the "dead letter of the law." Users often invoked it. This is seen clearly in a thread from late March, in which user WhatsUp asks: "Is there a way that I check if I already contracted the virus?":

Gary125 Just call your doctor or nurse to find out.

WhatsUp The thing is that I believe that folks on the Internet know more than medical professionals nowadays. Every day we find out something new about the coronavirus. But doctors and nurses don't have any free time for reading and to keep up to date with the news now.

HilaryNY That really is a ridiculous justification.

James2020 Please don't just rely on Professor Google. Consult a hospital's medical phone line just to make sure. A lot of the facts you may find on the Internet can be hearsay and is distorted in a game of telephone. There are falsehoods out there and panic only breeds more distortion. While I agree with you that doctors can lag behind, I would trust a professional over social media or a search engine.

In this exchange, WhatsUp was quickly reprimanded by others for a question that they thought should be directed to medical experts. And yet, WhatsUp's skepticism 
about medical knowledge was not an anomaly on Covid-19 Together, as indicated by James2020's last sentence. Many other users expressed a similar sense that because of the fast-paced development of knowledge surrounding Covid-19, credentialed experts and codified scientific knowledge-knowledge that has gone through peer review or incorporated into medical protocols - was not necessarily the most accurate or useful. Another poster, CovidNavigator, made a similar point while writing about their month-long battle with Covid-19:

When I started to search for trustworthy information on Covid-19, I found that a lot about the Covid-19 was still unknown and experts are just coming up with best guesses. The science is still in its infancy. It is unclear why some people only display mild symptoms while others end up on a ventilator. All experts have are hypotheses based on viral load, gender, blood type, co-morbidities, and what have you.

As you go through this labyrinth of facts, try to determine for yourself what is probably true, what is likely false, and what is just opinion. Consult sources you can trust. But, do not instantly assume that those with authority are right, regardless of whether they are public officials or medical professionals. The situation and knowledge is changing all the time.

This sums up the dilemma faced by users on Covid-19 Together (and perhaps by the public at the beginning of the pandemic): the rule of "no medical advice" divides the world into two neat little boxes. Users can be credible, it says, as long as they speak purely about their personal experience. General statements or medical advice, on the other hand, are credible only if they come from doctors and scientists. Yet maintaining the division between the boxes proves impossible. It is hard to determine what is significant and relevant about one's personal experience without "trustworthy information" from experts, but users have "to determine for yourself" what is credible and "true" in what the experts say (for a similar dynamic, see Reich 2016). Radical uncertainty is thus both an obstacle and an opening/resource for users. How, then, can users speak credibly and provide meaningful feedback to others about Covid-19? The rule is meant to provide guidance for recognizing and exhibiting credibility under conditions of radical uncertainty, but it does not work without knowing how to follow the rule. When is it and for whom, for example, that to violate the letter of the rule is to uphold its spirit?

In the following sections, we detail two key findings that explain how users were able to exhibit and recognize that they and others were following the rule, despite, or perhaps by virtue of the radical uncertainty that they faced, and how they could provide others with useful medical advice. First, when examined individually, a credible performance of advice-giving on Covid-19 Together required a hybrid interlanguage that blurred medical and personal advice and that created resonances between scientific and experiential terms. Second, taken sequentially, such a hybrid interlanguage could not be successfully drawn upon by all users but only by ones who have gone through a distinctive process of gradually accumulating credibility as lay experts on Covid-19 Together. 


\section{Performing Credible Lay Expertise}

What is a credible performance of lay expertise? There are really two questions here. First, how would we recognize a performance of some sort of expertise when we see it? And second, how do we measure whether this performance is credible or not? To begin with the second question, as mentioned, we define a credible performance along the lines of Goffman's (1959) dramaturgical theory of social interaction using the audience's response. When users convince others on the forum that they know what they are talking about, they are met with multiple affirming replies, with others concurring and complimenting their post. When a user's post is judged uncredible, others question the user's understanding of the topic, the veracity of their claims, and the honesty of their motivations. The lapse of credibility can also be measured by the breakdown and end to a discussion thread. Credibility, therefore, is operationalized using the measure of total "likes" and "dislikes" on a post.

We inductively identified several patterns that differentiate the top 1,000 from the bottom 1,000 scoring posts. We find that posts in the top 1,000 fell into several categories: posts that detailed illness experiences (29\%), gave useful advice to others (22\%), expressed encouragement, gratitude, or sympathy towards other users (17\%), cautionary tales and reports of deaths (13\%), questions for other users that were deemed to be relevant (12\%), and stories of success and recovery that comforted those who were still fighting the illness (7\%). Below, we analyze the interplay between medical and experiential knowledge in posts that gave advice deemed as credible to others. We specifically use this category of advice-giving to operationalize the credible performance of at least minimal lay expertise. We will try to show that when dispensing advice, members rely on a hybridized interlanguage that blended personal experience with scientific research: users frequently presented themselves as non-experts, prefacing their posts with phrases like, "I'm not an expert" or "I'm not a medical professional," but showed willingness and competency in searching for and understanding scientific research related to Covid-19 while translating these findings into practical and everyday terms. ${ }^{7}$ In the next section, we draw also on the category of posts that detail personal illness experience to demonstrate that there was a distinctive sequence by which this competency and recognition as lay experts was gradually acquired.

In contrast, posts from the bottom 1,000 fell into several other categories: statements that users attempted to pass off as "facts" without explanation (27\%), ad hominin and offensive insults (24\%), posts that were overly skeptical of others' personal accounts (17\%), posts that downplayed the severity of Covid-19 (15\%), off-topic rants $(11 \%)$, conspiracy theories (3\%), and excessive fear-mongering (3\%). The "fact" category specifically will serve to operationalize claims to lay expertise that were deemed as not credible by other users. Examples of such low scoring posts include, "I believe hydroxychloroquine, azythromicin, and ivermectin should be given early on," "just take lots of vitamin D and you'll be fine," but also non-factual

\footnotetext{
7 While there were users who made mention of their backgrounds in medicine or science, these identities were not given much credence by others, as users could not easily verify these claims.
} 
general strictures like "you should just trust your doctor and ignore what you find on the Internet." These "facts" or general claims could be understood as attempts to invoke credentialed expertise in a way that was deemed uncredible by the audience. We will try to show that the low scores for these posts did not mean that other users thought that patients should not take vitamin D or that doctors are inherently unreliable, but instead reflected the sense that such advice was given without performing the work of fashioning resonances between scientific terms and personal experiences. Had users bothered to explain the benefits of vitamin D combining personal experience with biomedical evidence or explained under what conditions doctors should be trusted (or ignored), and had these users gradually accumulated recognition as lay experts, these posts would likely have scored higher. Claims that were easily discredited as unscientific such as posts touting homeopathy were also seen in these low scoring posts. It is clear that despite the rule of no medical advice and the nominal deference to medical expertise, there were plenty of instances where users did offer medical advice to each other. This was because the boundary between what was considered "first-hand" experience and "medical advice" was often blurry, and because credible advice drew on an interlanguage that created resonances between medical and experiential knowledge.

A common form of lay expertise on the forum was to provide advice about home remedies and supplements that users claim to have aided in their recovery. Take for instance this exchange from ExistingConditions with 28 likes from the end of March, typical of discussions about the role of supplements in treating Covid-19:

ExistingConditions I am on day 15 of Covid. I have a ton of preexisting conditions like asthma, and am suffering from shortness of breath. I've talked to PCP, my friends, cardiology specialist, friends in medicine, and tried to research on my own. There's not a lot of peer reviewed studies on self-treatment on Covid-19 done. But this is what I've been doing based on existing evidence of things you can do to help with respiratory illnesses with the lowest risk of harm: (a) Sleep in slightly warm, humid air; (b) use a pulse oximeter; (c) Vick's vapor rub and ginger lemon tea (obviously not evidence-based); (d) drink a lot of water and rest!; (e) $2500 \mathrm{mg}$ Vitamin C two times a day, 25000 IU Vitamin D once a day for five days, N-acetyl Cystine 2,600 mg two times a day. Avoid those deficiencies! I'm feeling better in the past few days, so this might help.

RedRum You're ticking a lot of the right boxes except for the overloading of Vitamins. That's really not backed by any science. [post disliked by multiple users]

ExistingConditions There is definitely evidence that D deficiencies are correlated with worse outcomes for respiratory illnesses. Mixed evidence for $\mathrm{C}$.

BadWeather This post was super useful. But is it safe to take so much Vitamin D? 
ExistingConditions Vitamin D is fat soluble, so you can overdose on it. Have you ever had your levels checked? If they tend to run low, I'd definitely work on supplementing right away. I have mine checked at least yearly, and mine run really low. I usually take 5000 IU a day, which is pretty high for most people. If yours run normal, I think a more regular dose might be 2000-4000 IU a day. 25,000 is a very high dose, that my doctor recommended that Covid patients do only for five days. But don't stay at that kind of dose for any real length of time unless under the direction of a doctor. But I'm not a doctor! So, ya know, check my recs with the research out there and your own doc... Take care.

[...]Equestrian123 See this link. It contains reviews of existing studies on practices linked to better outcomes for respiratory illnesses! https://necsi.edu/respiratory-health-for-better-covid-19-outco mes

SigmundF

I can confirm all the things you all recommended! I would only also suggest that you add electrolyte tabs in your water. Staying upright, as you suggested, also helps. I stayed upright most of quarantine... I'm getting a lot better. My fever and symptoms are disappearing, coughing less, and I can close my eyes now and rest without fear of drowning my lungs.

Users in this exchange freely drew from both personal and scientific evidence to justify their selection of supplements, while debating the merits of different dosages and vitamin cocktails. There are several noteworthy elements in ExistingConditions' post that exemplify what makes a performance credible, or as RedRum says, "ticking a lot of the right boxes": first, establishing that one is not claiming to speak as a medical expert but on the basis of personal experience. ExistingConditions' post is bookended by an initial claim to have credible relevant experience ("day 15 of Covid"), and a concluding qualifier that-“I'm not a doctor" and carefully cautioning those pursuing these forms of self-treatment to consult with credentialed experts. Second, presenting oneself as non-dogmatic. ExistingConditions reports consulting both medical professionals and "friends," without prejudging in advance which source is more credible. They also calmly admit to uncertainty and to the limitations of both the literature ("mixed evidence for C") and personal experience (ginger lemon tea is "obviously not evidencebased"). Third, this non-dogmatism allows ExistingConditions to move back-andforth between displaying technical facility with the literature ("fat soluble") and individually tailored, practical advice based on their experience ("I have mine checked at least yearly"). Fourth, the move back-and-forth is facilitated by concepts like "respiratory illnesses," which create resonance between personal experience (most people have had some experience with an illness that affected respiration) and medical research. Another concept providing such resonance is of course "vitamins." It resonated widely because it contains within it the idea (and everyday practice) that patients could take control of their health outcomes, yet 
guided by scientific research and doctor's advice (requiring ExistingConditions to calmly but firmly swat away RedRum's objection). This was particularly true for Long-Haulers, where symptoms or fatigue from the virus extended for over a month, and where credentialed experts seem to offer little useful advice.

Breathing exercises were also popular amongst users on the forum who were having difficulties with Covid-19 symptoms such as coughing and shortness of breath. Take for instance this thread from BaldEagle, which received over 700 likes from the end of March:

BaldEagle Hi folks, as you know, coughing is exhausting and draining for your body. You should check out this video on Active Cycle of Breathing Technique (ACBT), which helps you clear your lungs more efficiently https://bronchiectasis.com.au/physiotherapy/techn iques/the-active-cycle-of-breathing-technique. This is taught by physiotherapists to help patients clear out secretions in our lungs. There are three different breathing pathways that you can try to see which works best for you: Breathing Control (BC), Thoracic Expansion Exercises (TEE), and Forced Expiration Technique (FET). For BC, try to breathe using the lower part of your chest with your diaphragm while relaxing your shoulders. For TEE, focus on slow breathing and holding your breath at the end (you can alternate TEE with BC). For FET, it is okay if you need to cough but try huffing as if you are steaming up a mirror in front of you.

NYProf This worked excellently for me! Thank you so much. I have heard medical professionals recommend this for patients of respiratory illness. This is also featured on this article about COPD https:// mylungsmylife.org/topics/group-1/how-to-clear-your-chest/sputum-benefits-and-downside/

LakeMichigan Coincidentally, my physiotherapist is also working with me on these breathing techniques. The links you all provided seem great, I will try them out. I used to run a lot, so theoretically, I should already know how to breath, but I am learning a lot from you all. I would also advise people to work on Diaphragmatic Breathing, seen in this video https://youtu.be/5Pfde986Xps. Those who are not yet severely ill should learn this before their conditions worsen.

While BaldEagle does not explicitly claim to be a patient or an expert in this post, BaldEagle made their advice on breathing exercises "user-friendly," demonstrating intimate familiarity with the techniques. Significantly, users draw here on knowledge and expertise from a paramedical specialty - physiotherapy — which, because of its subordinate status, has always sought to recruit patients as allies by giving them an active role to play in their treatment. Subsequent posts from other users build on BaldEagle's advice and amplify its resonance by, on the one hand, linking it with 
the recommendations of "medical professionals" and, on the other hand, confirming that these breathing exercises have helped them manage their symptoms. Credibility, in this case, was a collective achievement sustained by the contributions of multiple users.

The features that allowed the above advice to be credible - the intertwining of the experiential and the scientific_-stands in sharp contrast when we compare it with a discussion on self-isolation that ended up in acrimony and accusations of dogmatism when a user appeals to credentialed expertise:

Cyclist121 My doctor presumed that I was positive and ordered that I isolate for 14 days AFTER my fever dropped. I said what about CDC saying 72 hours? I was told no. 14 days. For what it's worth, I know there's a lot at stake and a lot of different information.

YourFriend Unfortunately this is not realistic advice and it is also against CDC guidelines.

NYCPatient From the CDC: https://www.cdc.gov/coronavirus/2019-ncov/ifyou-are-sick/steps-when-sick.html. Home isolation for people with COVID-19 can be discontinued under these conditions: if a test is conducted to see if you are contagious; if you have no fever for at least 72 hours (without medication) AND other symptoms have improved AND at least 7 days have passed since your symptoms first appeared.

Ghost3333 Why are people still believing the CDC and their guidelines? They have consistently delivered misleading and reckless advice that has been disproven and that goes against common sense. [...]I would just treat it as Schrödinger's virus. Everyone including myself both have it and is contagious and also doesn't have it and is immunocompromised and act accordingly. Stay in quarantine until we know more. Don't risk further spread until we have antibody tests and have peer reviewed studies that tell us how long viral shedding goes on for.

OnTheVerge What are you talking about Ghost3333? The CDC is one of the only reliable sources of guidance, it's the public officials that don't listen to them that has been causing harm. What misleading/reckless advice have they been delivering? They have been releasing information as they learn more and constantly updating the public with their constantly evolving understanding of the virus.

Ghost3333 Covid-19 isn't airborne.' This was wrong. 'Don't wear masks they're not effective.' This was wrong. 'Just wash your hands and don't touch your face.' This was wrong. 'Asymptomatic people can't spread the virus.' This was wrong. 'The virus can't spread on packages.' This was wrong. 'Just quarantine for 14 days if you start feeling sick then you can pop back to work and be around you grandparents again when your symptoms have gone.' Whoops you've been symptom free for a week but you are still testing positive, our bad... 
Those blindly following official guidelines and not using their own common sense are endangering everyone.

NYCPatient's response to Cyclist 121's question is to recite the official guidance provided by the CDC. Neither they, nor YourFriend, attempt to embed in or link this guidance with personal experience. For this reason, they are perceived by Ghost3333 as "blindly following [misguided] official guidelines and not using their own common sense." In the controversy that ensues, all sides dispense medical advice and descend into a political dispute about trust in public health expertise. Instead of intertwining personal experience with medical knowledge, the discussion ends at an impasse. The advice dispensed by credentialed experts is discredited, but the appeal to "common sense" is also empty because its only content seems to be "don't trust the CDC." In separate threads, users also ridiculed the 14-day rule:

StillSick I'm on day 30 of Covid and I'm still feeling it... my family thinks I should have recovered by now and that I'm just insane.

CovidSucks I'm on day 55! Someone told me that I was done and I'm now just in recovery. But I still have the same symptoms. It's frustrating when they tell me how I'm doing or should be feeling... It's such a new virus and nobody really understands it...

LakeMichigan I'm on day 40 and it's still hitting me in waves. I'm just so exhausted. Still have my shortness of breath and GI issues... I'm tired of Internet randos telling me that I'm just having the 'regular flu.' No idiots, I have 14 of the 14 symptoms. 'But it just lasts 14 days.' Yeah sure. I've read your extensive study in The Lancet. For crying out loud. Even the actual 'experts' have no clue because, maybe, I don't know, this is unprecedented?!

The radical uncertainty of Covid-19 was therefore a resource that users invoked to downgrade the credibility of proclamations from credentialed experts and create an opening for drawing on personal experience as a valid, credible source of knowledge. This allows us to say something about the much-bemoaned issue of mistrust in experts. What was distrusted on Covid-19 Together, or put more descriptively, what was easier to discredit, were uncontextualized assertions that aimed to borrow credibility from "science" or from the official status of the experts. This was characteristic of the "fact" claims that users in the bottom 1000 scoring posts invoked. While the explicit rule was to encourage users to consult with the doctors, the unspoken rule was to frown upon any assertion that derived its sole force from being spoken by a doctor. It is telling that, when doctors and nurses weighed in on Covid-19 Together, they often felt the need to emphasize that they too tested positive for Covid-19: 
InfectedFamily I'm confused. My mom and brother both got Covid-19. My father, who is old and pre-diabetic lives with them in close quarters was tested multiple times and was negative throughout the ordeal. Was it possible he was asymptomatic and just had no symptoms? It's just strange that my healthy younger brother had the severe symptoms...

FemaNP Yes, that happens! I am a disaster relief nurse for a Covid treatment center that was swamped with patients. A lot of us on staff tested positive. When I started working there, everyone in my household quarantined and stayed away from each other. I stayed upstairs but still shared the same bathroom and kitchen in our small 900 square feet home. When I came down with Covid a few weeks ago I tried to disinfect everything. But there were times when I couldn't muster the energy to be as thorough. I'm symptomatic and should be contagious. I really don't know why they haven't caught Covid from me yet... I'm also the youngest, which makes no sense to me.

The credentialed expert here was able to seamlessly combine the roles of credentialed and lay expert, each lending credibility to the other. To summarize: a credible performance of expertise on Covid-19 Together during this situation of radical uncertainty, as measured by the audience's reaction, was characterized by the ability to move back-and-forth between personal experience and the interpretation of scientific research in a way that built resonances between the two, and that was seen as congruent with and useful for the experience of others.

\section{Becoming a Lay Expert}

This script of credible performance is something that can be learned and accumulated over time by users on Covid-19 Together, culminating in an achieved status of lay expert. Two patterns were observed in our analysis of the trajectories and careers of the top 100 active users. First, these users began their engagement with the forum by asking questions about the experiences of others and posting about their own illness experience. They began, therefore, in the experiential register and by soliciting advice from others. In the next stage, however, and this is the second pattern we observed, these users proceeded to offer credible advice to others by drawing on their experience, comparing it with the experience of others, and intertwining their account with official sources of information that supported their advice. They now added a biomedical register to their voice, based on critically reading news articles and scientific literature. Yet, their credibility depended on carefully calibrating this register as supportive evidence for the lessons they gleaned from their experience. At this point, users become credible lay experts who offer other members of the forum advice on how to manage their disease. They often bring in their personal experience and recommend supplements, diets, and medications that worked for them. Yet, just as often they link to sources of information that would support 
their suggestion. It is important to note that these kinds of links are exactly what the forum's rules frown upon as constituting medical advice not from personal experience. The ability to deploy them depends on carefully intertwining them with personal experience-thus sticking to the spirit of the rule while violating its written letter-and accumulating over time the recognition that would endow them with resonance. These links ultimately work because they resonate, but they resonate because they work.

This trajectory is seen clearly in the career of user SympatheticPatient, who contributed over 700 posts, and has been dealing with a long-haul case of Covid-19. The user begun by asking generic questions like "How are you feeling?" in threads where users were describing their symptoms in late March. This enabled them to compare their experience with others. After soliciting illness experiences from other users, and finding them similar to their own, SympatheticPatient became convinced that recovery from Covid-19 would take longer than they had previously anticipated. As they wrote in April: "Your experience with Covid sounds exactly like mine. I get tired from just walking to my mailbox." By late April, the user began incorporating previous studies of chronic fatigue syndrome and post-viral illness into their posts. They would often begin their posts with phrases like "all the studies that I have read suggest that." In a reply in May to another user posing questions about the recovery experiences of other users, SympatheticPatient pointed to the experience of SARS patients: "According to studies, a large percentage of SARS 1 patients, mostly healthcare workers, suffered from long-term symptoms of fatigue." As they noted, because Covid-19 is a novel illness, little is known about its long-term effects; but past experiences of comparable viruses may be of use. By June, the user frequently suggested different drugs and supplements to others, referencing scientific literature as well as their own experience. To manage their lingering symptoms, SympatheticPatient would recommend a supplement regimen: "I' $m$ taking Vitamin D and C, Zinc, Glucosamine, Quercetin, NAC, Flaxseed Oil, Magtein, Nattokinase, Probiotics, small doses of potassium. Obviously hard to say what effect these have, but I felt better when I started taking quercetin. The NAC looked like it helped with my breathing... I've read effects last 8 hours." Users seeing this advice often expressed gratitude and offered slight modifications to the regimen based on their personal experience and articles that they have read online. Yet, if another user barged on the scene and with their very first post offered the same list of supplements as SympatheticPatient, they would likely have been seen as quixotic and untrustworthy. The very same advice would have lacked resonance without the backing of an established track record. SympatheticPatient's case was relatively straightforward. They were able to acquire recognition as lay experts by first foregrounding their bona fides "lay" status: asking questions, comparing experiences with others, and finding similarities. Only once they were secure in this status were they able to play the role of "expert" and begin sharing and recommending biomedical knowledge and ultimately providing hybrid advice to others. Top users can also confer a degree of credibility to relative newcomers if the experienced user engages in or post affirmatively in the newcomer's thread, demonstrating the role that mediators within the patient group played in shaping the collective recognition of credible lay expertise. 
It is important to emphasize that belonging to the group of 100 most active users coincided only partially with credible lay expertise. Some users went through the stages of the trajectory of the process fairly rapidly. They "got it right" in their first few posts but did not necessarily continue. Conversely, some users posted frequently but never managed to strike the right balance. Their failure is instructive about what makes for credible performances. Take for instance, the example of user SevenUp, who contributed over 250 posts, but failed to be recognized as credible. Unlike SympatheticPatient, SevenUp's advice was never sought or favorably received. SevenUp's initial trajectory was similar to SympatheticPatient. They started posting in late March, asking others how they felt and sharing their initial experiences with Covid19. In April, SevenUp started posting longer posts about their long-haul symptoms and continued asking questions about symptoms: "Is neck pain a symptom of Covid-19? I haven't seen this written about elsewhere but wanted to know if anyone else on here has had that experience." Occasionally, SevenUp offered messages of encouragement, "Hopefully you'll feel better! Wishing you luck at the end of Week 5 over here." This should have made users well-disposed towards SevenUp. From here onwards, however, SevenUp's trajectory diverged from SympatheticPatient's. They did not venture beyond asking questions and offering their own experience. They did not incorporate research findings into their posts, nor sought to establish resonances between their experience and biomedical research. Gradually, other users became suspicious. A longer post from late April, detailed SevenUp's unsuccessful attempt to get medical care at a hospital, despite reportedly "coughing up blood" and "losing control of my limbs." This post, however, was removed by the moderator for "fear-mongering." Other users reacted negatively and suggested that SevenUp was "suffering from severe anxiety," or was simply "delusional," perhaps suffering from Munchausen syndrome. Members of the forum, therefore, began to think that SevenUp's symptoms were perhaps "all in their head." Users did not seem to think SevenUp's symptoms were credible because their reports lacked resonance either with their own experience or with reports from the biomedical literature. After this incident, further posts from SevenUp were often dismissed. Ultimately, SevenUp stopped posting in early June.

We interpret the contrast between these two cases as indicating another function of the hybrid interlanguage spoken by credible users on this forum. This observation is also more generally relevant to the literature on lay expertise. Typically, command of scientific language and evidence is considered important for establishing a lay expert's credibility with official experts, while the sharing of personal experiences understood to be important for establishing one's credibility with other sufferers. We also have emphasized the latter part in our analysis up till now. What we would like to suggest now, also, is that somewhat paradoxically, command of the scientific evidence and language, and especially the ability to establish its resonance with typical experiences, serves as an essential resource for lay experts to convince other affected persons of the relevance of their personal experiences. As Barker (2008) notes, the "strong desire to frame one's suffering within scientific medicine's core assumptions demonstrates that medical discourse still garners significant cultural authority" (29). How do people know that they share disease experience with others? How do they know that their symptoms are "the same" as the symptoms of 
another sufferer? There is evidence that it requires rhetorical work (and sometimes legwork) of persuasion, furnishing of evidence, and the drawing of analogies such as with "respiratory illnesses" or to "SARS 1" (Arancibia and Motta 2019; Brown et al. 2004). Drawing on scientific language can play an important role in turning subjective, disconnected complaints into a shared illness experience. Similarity of symptoms cannot, by itself, achieve this transformation because there are always going to be interpretive discrepancies between complaints and because their significance depends on attributing credibility to the complainer. In the cases described above, SevenUp, who did not draw on scientific language and evidence, was ultimately judged a non-credible complainer. Other users were not convinced that they shared the same symptoms. The counterfactual is that a discussion board composed only of "SevenUps" would have been unlikely to cohere into a shared illness experience.

This careful choreography of lay expertise-weaving together personal experience, comparisons with the experience of other patients, and the use of scientific knowledge and language_- can also be seen in a thread from early April, titled "It Gets Better: Here's my Experience with a Mild Case," by a user named DogLover115, who contributed over 70 posts. 790 users liked this post. As the title indicates, this is a personal account of DogLover115's 40-days long experience with Covid-19. It begins not with a claim to expertise, but with an expression of encouragement, sympathy and connectedness with other forum members. DogLover115 writes, "I want to let everyone reading this who are anxious to know that I am slowly getting better, and chances are this will be the case with lots of folks. I hope you will find some use of my documentation." What follows is a very detailed account in which DogLover115 takes a semi-scientific attitude to their illness, dutifully measuring and recording symptoms, and constantly comparing their experience with the lists of symptoms found on official sources. DogLover115 experienced noticeable symptoms for about 15 days, starting with an itch in the back of their throats and a warm feeling that developed into a fever by day 4. DogLover115 dutifully recorded their temperatures 2-3 times a day, and employed a "symptom severity scale" of their own making ranging from 1 to 10 . All the while, they also noted the subjective feelings of illness. By day 6, DogLover115 had started noticing a loss in smell and taste-a telltale sign noted by many other forum users even before the widespread reporting of the symptom in the news media. DogLover115 explains that they detected this through what they called "the coffee test": "I was able to tell with my morning coffee. I couldn't smell the coffee when it was brewing or when I was holding it in front of me." This loss of sense of smell resonated with other users. As user QuietReader chimes in, "Whoa! Reading your story gives me flashbacks to when I dealt with this in February... My throat felt raw and burnt, and I couldn't smell and taste anything." The coffee test is a good example of how credibility is claimed and deployed. DogLover115 draws on their experience and other users' experience, compares this with official medical reports, and ends by offering other users a practical test that anybody can perform in their kitchens. While this may seem a somewhat trivial example, what stands out about it from the point of view we develop here is the fact that DogLover115's contributions were well-liked and did not lead to controversy. The claim to expertise here was certainly modest, but perhaps precisely for this reason, it was also credible. 
As indicated above, the capacity of users to speak beyond their own illness experience is a crucial component of lay expertise. While users draw on their experience to compare and generalize across cases, biomedical knowledge can also be used to bolster a user's understanding of their own illness experience and - when brought in carefully - to share their own illness experiences with others. This can be seen through the links shared most frequently on the forum. ${ }^{8}$ Users tended to favor sources directly from scientific literature that describe novel findings. This included links to the studies themselves or news articles and blog posts that covered the findings. For instance, the most shared scientific article is a preprint from Poletti et al. (2020) titled "Probability of symptoms and critical disease after SARS-CoV-2 infection" that analyzed the symptoms of 5,484 Covid-19 cases in Italy and described risk factors of critical disease. Other studies that were frequently shared include findings that the loss of smell and taste was associated with Covid-19 and the prophylactic usage of Zinc and vitamins. There were also links to Youtube, such as a video titled "Recovering from COVID-19 / Can Coronavirus cause Post Viral Fatigue?" uploaded on April 30, 2020, which discussed studies related to Post-Viral Fatigue Syndrome (PVFS) and goes on to describe the vlogger's personal experience with PVFS. In their words, "I wanted to make this film to put the word out there to other people out there like me who are maybe still suffering two months after an initial infection to say you're not mad, it's not in your head." This phrase is especially telling because SevenUp, after all, was judged by other users to be somewhat "mad," their symptoms somewhat "in their head." This genre of video is representative of the same hybrid interlanguage seen in Covid-19 Together. It illustrates the role that this languageespecially the ability to build resonances between scientific research and personal experience-plays in stabilizing illness reports, removing the suspicion of subjectivity ("in your head") and allowing symptoms to become shared. In contrast, official guidelines from CDC and the FDA were less frequently shared. This suggests that users preferred to go directly to the experiential source or the scientific source, without the layer of mediation represented by these institutions. As we noted earlier, without context, citing these official guidelines appeared to users as assertions from authority. This is important to understand regarding the current perception of popular mistrust of science and experts. Users did not reject science, but they did question the intermediary role of the public health expert in this radically uncertain situation. The public health expert exercises honed judgment to assess different studies' value based on their rigor and quality. But this judgment is mixed with other logistical, financial, and legal considerations-as was evident in the Surgeon General's disastrous tweet that facemasks "do not protect from Covid-19" - and then translated into official guidelines and cutoffs (e.g., "positivity rates"). Without carefully parsing these considerations-which itself runs the risk of descending into multiple debates about evidence, values and

\footnotetext{
${ }^{8}$ In total, there were 744 unique links that were shared 3,421 times on the forum. These links are helpful in understanding the sources of information drawn upon by users of the online community. Links to other parts of the forum (e.g., to the rules or other posts) were removed.
} 
judgment-following the guidelines appears dogmatic and uncredible. To reiterate, scientific knowledge, such as the research articles in these links, was integral for users in their attempt to understand the day-to-day experiences with Covid-19. Still, they preferred to rely on the collective lay expert judgment that developed on the forum.

There were instances where personal experience was not referenced, with users debating a particular study's scientific merits. Users do this at their peril as moderators may shut down discussions that venture too far off from personal experience or seem to look too much like medical advice. Those who engage with such discussions tend to either have accumulated lay expertise, or have prior exposure or training in the relevant scientific fields. This was seen in the case of discussions over the potential dangers of using Ibuprofen, following reports that Ibuprofen may increase the severity of Covid-19. In a thread from mid-March from Hamster9090 titled "Could use some help. I feel awful," a discussion over how to suppress a fever unfolded:

Hamster9090 I feel terrible. I'm experiencing shortness of breath, nausea, chest pains, aches all over, chills, malaise, giddiness... I want to get tested tomorrow but the clinics are running out of tests. Is there anything I can do to make myself feel better meanwhile?

[...]Summer151 Use medicine to lower your temperature like Tylenol, Ibuprofen, if you develop a cough keep sucking on cough drops to repress it, keep your intake of fluids up, if you can manage food eat small amounts at a time, the main thing is keeping you hydrated and your calorie count up, I hope you get better and can get medical treatment as soon as possible

LurkingUser Do not take Ibuprofen. Studies in France have shown it to have a really negative impact on those infected. Take paracetamol or Tylenol!

SmoothJazz It is not a French study, though the French Health Minister did Tweet about it. It was a letter to Lancet hypothesizing that ACE inhibitors and Ibuprofen may increase susceptibility because of known effects on cell surface density of the particular receptor the virus utilizes to gain entry. There are no empirical studies yet. The letter was published only a few days ago, although there certainly will be studies soon.

\section{MiamiSoul \\ LurkingUser} Link please.

Apologies, should have provided the link right away. https:// www.theguardian.com/world/2020/mar/14/anti-inflammatorydrugs-may-aggravate-coronavirus-infection

CovidQuestions Absolutely no medical experience whatsoever here, just questioning as a novice, isn't fever helpful when fighting a virus? Why would you want to repress your immune response in a time like this? 
Lychee09 You'd want suppress your immune system because of the cytokine storm. It's the immune response that kills people. People of going from mild symptoms to organ failure.

LiveYourLife Lychee09

James999

$[\ldots]$ Ohio12
What should we do then?

I don't know. It's dammed if you do, and dammed if you don't. I read an article, where China has been administering vitamin C intravenously to mitigate cellular damage caused by the cytokine storm.

There is also a trial using tocilizumab, a monoclonal antibody that inhibits one of the cytokines (interleukin 6 or IL6) showing great results so far.

Not a doctor, but a middle school science teacher. I explained it to my students like this: 'A fever is much like a game a game of chicken. Your body is raising it's temperature in the hopes that the temperature change kills the virus in your body before it shuts down your organs.' Tylenol can lower your fever before it gets dangerously high.

The exchanges discussing Ibuprofen did not draw on personal experiences at all. Rather, users drew extensively from existing biomedical knowledge and provided each other with medical advice, seemingly in direct contravention of the forum's rules. And yet the discussion was not flagged, nor did it descend into acrimonious accusations. This is probably because users were careful to preface comments with the disclaimer "I'm not an expert, but..." (CovidQuestions and Ohio12). How the forum's spirit, if not its explicit rules, continued to be present in this discussion, was captured in MiamiSoul's ability to simply say "link please" and "LurkingUser's" immediate apology, acknowledging an apparent deviation; and in Ohio12's use of a simple metaphor, of the game of chicken, to appeal to other users' common sense.

To summarize: to become a lay expert on this online community, users adopted a pragmatic stance towards credentialed expertise. They were able to pick and choose scientific research that resonated with their personal experiences, though no doubt they also learned to reinterpret their experiences to produce this resonance. To enjoy credibility on the forum, users developed the ability to report their embodied, personal experiences in a semi-scientific register. For scientific knowledge to be authoritative in the forum, it had to resonate with personal experience. It had to carry the marks of a personal taste in selecting what and whom to believe. This hybridity was part of the script for a credible performance of lay expertise during the radically uncertainty of the Covid-19 pandemic.

\section{Conclusion}

By using Goffman's dramaturgical theory of social interaction, this study of lay expertise on Covid-19 Together showed how a hybrid interlanguage was deployed by users to gain credibility and give advice to each other during the radical uncertainty of the pandemic's initial months. Through asking questions and speaking to 
one another, users learn to play the role of the lay expert, and acquire the capacity to speak beyond their own illness experiences by comparing and generalizing from personal experiences and by linking these experiences with scientific knowledge that is resonant. By tracking the audience's reaction to attempts at advice-giving, we found that the types of credentialed expertise that resonate with users on Covid19 Together included knowledge congruent with a patient's illness experience and knowledge that helps solve problems that the patient encounters. Through this process, biomedical knowledge becomes integral to shaping the collective illness identity of affected patients, by enabling patients to constitute an audience of peers that recognize similarities in otherwise disjointed illness experiences.

This script of hybrid interlanguage for performing credible lay expertise may also be observed in other patient communities in varying degrees. But as Goffman would point out, new audiences and situations may require adjustments to the performance of lay expertise. What made this hybrid interlanguage particularly credible was the radical uncertainty at the pandemic's onset. When this uncertainty subsides, such a strategy may not be needed, as patients can simply draw either on their own experience or on scientific knowledge to make their claims. But one could also see the hybridity of lay expertise on this forum as enabling patients to prepare for their interactions with policymakers, physicians, and researchers. In this way, the forum itself can be seen as a backstage in the longer development of lay expertise. Stepping out of spaces like Covid-19 Together and in front of different audiences and onto different stages necessitates changes in how patients speak, such as by citing medical protocols, the latest research studies, and the telling of particularly moving anecdotes. Thus, the hybridity and the interlanguage observed in this online community can serve as a staging ground for preparing future interventions. As patients learn to speak beyond their own illness experience and generalize from their case, they may eventually learn to speak for the patient community, mobilizing fellow patients to demand more from policymakers and researchers. Future research on the interactional and performative dimension of expertise should also pay attention to the different roles patients can play within patient groups, such as the role of the mediators that lends credibility to newcomers.

Additionally, thinking of lay expertise as a hybrid form of expertise enables us to consider the implications of the politicization of expertise seen in the United States and the contested cultural authority of science in this historical moment. Users' preference to avoid advice from public health authorities and institutions of regulatory science and go directly to pre-prints and the latest scientific article reflects the broader mishandling of the pandemic. The phrase "I'm not an expert, but..." that is repeated on the forum should not be interpreted as only a disclaimer that the advice dispensed by users is "not scientific" but also as a strategy for users to continue to help others while side stepping the mistrust of experts. As Goffman (1955) details in writings on face-work, participants in social interactions go to great lengths to preserve lines of communication. To invoke Goffman (1986), again, this performance of lay expertise attempts to avoid the current stigma and spoiled identity of credentialed experts. By presenting themselves as "just a patient," users on the forum gradually acquire credibility and contribute to ongoing discussions about Covid-19 without causing more controversy. Further research on expertise in this moment of crisis 
can further shed light on what other performances of expertise can resonate across social, political, and cultural divides.

The long term impact of Covid-19 on the subgroup of patients with enduring symptoms-Long Covid or Long-Haulers-will be an area where lay expertise will undoubtedly shape the development of biomedical knowledge. A November 202060 Minutes segment profiled Covid-19 Long-Haulers suffering from lingering symptoms months after their initial diagnosis (Cooper 2020). The Long-Haulers interviewed in the segment reported that they initially faced significant difficulties in getting medical professionals to take seriously their complaints. Patient Nitza Rochez recounted her experience at the emergency room: "The doctors were like, 'You're fine. You're having anxiety attacks. You're nervous. Breathe... They thought it was in my head." Only once she arrived at Mount Sinai Hospital's Center for Post-Covid Care, was she able to find physician-researchers who believed her. When asked why those at the Center believed in the experience of Long-Haulers, Dr. Dayna McCarthy replied: "I have to. Because I feel those symptoms too. And I don't think it's all in my head." Their shared experience as Long-Haulers, Dr. McCarthy suggested, allowed the medical personnel at Mt. Sinai to recognize the long-term effects of Covid-19. But, of course, it was also crucial for Nitza Rochez that these were credentialed medical experts who validated her symptoms. Without the combination of shared experience and medical authority, patients like Rochez would have been left thinking that "it's all in my head." Already, groups such as The Body Politic, The Patient-Led Research Collaborative, and Survivor Corps are working with researchers to understand the effects of Long Covid better, converting the hard-fought lay expertise they developed within the patient community into credible performances of expertise that is recognized by medical, scientific, and policy audiences.

Acknowledgements The authors would like to thank members of Columbia University's Science, Knowledge, and Technology Workshop, Josh Whitford, Diane Vaughan, Joonwoo Son, Joshuamorris Hurwitz, Jack LaViolette, Humberto Fernandes, and Madi Whitman, for comments on the paper. The authors would also like to thank Jordan Brensinger, Adrianna Bagnall-Munson, Anna Hidalgo, Tiffany Huang, Greer Mellon, and Nicholas Pang for reading a much earlier draft, and Roberto Reyes for technical assistance. Additionally, the authors are grateful for the invaluable feedback that the editors and four anonymous reviewers provided.

Funding No funding was received for conducting this study.

\section{References}

Akrich, Madeleine. 2010. From communities of practice to epistemic communities: Health mobilizations on the internet. Sociological Research Online 15 (2): 116-132.

Arancibia, Florencia, and Renata Motta. 2019. Undone science and counter-expertise: Fighting for justice in an Argentine community contaminated by pesticides. Science as Culture 28 (3): 277-302.

Atkinson, Paul. 1984. Training for certainty. Social Science \& Medicine 19 (9): 949-956.

Barker, Kristin K. 2008. Electronic support groups, patient-consumers, and medicalization: The case of contested illness. Journal of Health and Social Behavior 49 (1): 20-36.

Barker, Kristin. 2009. The fibromyalgia story: Medical authority and women's worlds of pain. Philadelphia: Temple University Press. 
Barker, Kristin K. 2019. Lay pharmacovigilance and the dramatization of risk: Fluoroquinolone harm on YouTube. Journal of Health and Social Behavior 60 (4): 509-524.

Bloor, M. 2000. The South Wales Miners Federation, miners' lung and the instrumental use of expertise, 1900-1950. Social Studies of Science 30 (1): 125-140.

Brown, Phil. 1995. Naming and framing: The social construction of diagnosis and illness. Journal of Health and Social Behavior. https://doi.org/10.2307/2626956.

Brown, Phil. 2007. Toxic exposures: Contested illnesses and the environmental health movement. New York City: Columbia University Press.

Brown, Phil, Stephen Zavestoski, Sabrina McCormick, Brian Mayer, Rachel Morello-Frosch, and Rebecca Gasior Altman. 2004. Embodied health movements: New approaches to social movements in health. Sociology of Health and Illness 26 (1): 50-80.

Carr, E. Summerson. 2010. Scripting addiction: The politics of therapeutic talk and American sobriety. Princeton: Princeton University Press.

Carr, E. Summerson. Forthcoming. (In)Expertise and the paradox of therapeutic governance. In The Oxford handbook of expertise and democratic politics, eds. Gil Eyal and Tom Medvetz. Oxford: Oxford University Press.

Chahrour, Mohamad, Sahar Assi, Michael Bejjani, Ali A. Nasrallah, Hamza Salhab, Mohamad Fares, and Hussein H. Khachfe. 2021. A bibliometric analysis of COVID-19 research activity: A call for increased output. Cureus 12 (3): e7357.

Collins, Harry, and Robert Evans. 2009. Rethinking expertise. Chicago: University Of Chicago Press.

Cooper, Anderson. 2020. Puzzling, often debilitating after-effects plaguing COVID-19 "long-haulers." 60 Minutes. November 22. https://www.cbsnews.com/news/covid-long-haulers-60-minutes-2020-1122/. Accessed 1 May 2021.

Davison, Charlie, George Davey Smith, and Stephen Frankel. 1991. Lay epidemiology and the prevention paradox: The implications of coronary candidacy for health education. Sociology of Health \& Illness 13 (1): 1-19.

Deterding, Nicole M., and Mary C. Waters. 2021. Flexible coding of in-depth interviews: A twenty-firstcentury approach. Sociological Methods and Research 50 (2): 708-739.

Doanvo, Anhvinh, Xiaolu Qian, Divya Ramjee, Helen Piontkivska, Angel Desai, and Maimuna Majumder. 2020. Machine learning maps research needs in COVID-19 literature. Patterns 1 (9): 100123.

Dreyfus, Hubert L., and Stuart E. Dreyfus. 2005. Peripheral vision: Expertise in real world contexts. Organization Studies 26 (5): 779-792.

Dumit, Joseph. 2006. Illnesses you have to fight to get: Facts as forces in uncertain, emergent illnesses. Social Science and Medicine 62 (3): 577-590. https://doi.org/10.1016/j.socscimed.2005.06.018.

Epstein, Steven. 1995. The construction of lay expertise: AIDS activism and the forging of credibility in the reform of clinical trials. Science, Technology and Human Values 20 (4): 408-437. https://doi. org/10.1177/016224399502000402.

Evans, Robert, and Alexandra Plows. 2007. Listening without prejudice? Re-discovering the value of the disinterested citizen. Social Studies of Science 37 (6): 827-853. https://doi.org/10.1177/0306312707 076602.

Eyal, Gil. 2019. The Crisis of Expertise. First edition. Cambridge; Medford: Polity.

Eysenbach, Gunther, and James E. Till. 2001. Ethical issues in qualitative research on internet communities. BMJ : British Medical Journal 323: 1103-1105.

Fox, Renée. 1957. Training for Uncertainty. In The student physician, eds. Robert K. Merton, G. Reader, and P. L. Kendall, 207-241. Cambridge: Harvard University Press.

Frickel, Scott, Sahra Gibbon, Jeff Howard, Gwen Ottinger, and David Hess. 2009. Undone science: Charting social movement and civil society challenges to research agenda setting. Science, Technology \& Human Values 35 (4): 444-473. https://doi.org/10.1177/0162243909345836.

Galison, Peter. 2010. Trading with the Enemy. In Trading zones and interactional expertise, ed. M.E. Gorman, 25-52. Cambridge: MIT Press.

Giddens, Anthony. 1990. The consequences of modernity. Polity Press.

Goffman, Erving. 1955. On face-work. Psychiatry 18 (3): 213-231.

Goffman, Erving. 1959. The presentation of self in everyday life. Garden City: Doubleday.

Goffman, Erving. 1986. Stigma: Notes on the management of spoiled identity. Reissue. New York: Touchstone.

Heyen, Nils B. 2020. From self-tracking to self-expertise: The production of self-related knowledge by doing personal science. Public Understanding of Science 29 (2): 124-138. https://doi.org/10.1177/ 0963662519888757. 
Hilgartner, Stephen. 2000. Science on stage: Expert advice as public drama. Redwood City: Stanford University Press.

Jauho, Mikko. 2017. Contesting lifestyle risk and gendering coronary candidacy: Lay epidemiology of heart disease in Finland in the 1970s. Sociology of Health \& Illness 39 (7): 1005-1018.

Jutel, Annemarie. 2009. Sociology of diagnosis: A preliminary review. Sociology of Health \& Illness 31 (2): 278-299.

Kelly, Ann H., Javier Lezaun, Ilana Löwy, Gustavo Corrêa Matta, Carolina de Oliveira, and Elaine Teixeira Rabello. 2020. Uncertainty in times of medical emergency: Knowledge gaps and structural ignorance during the Brazilian Zika crisis. Social Science and Medicine 246: 12787.

Kempner, Joanna. 2014. Not tonight: Migraine and the politics of gender and health. Chicago: University of Chicago Press.

Kempner, Joanna, and John Bailey. 2019. Collective self-experimentation in patient-led research: How online health communities foster innovation. Social Science and Medicine 238: 112366.

Kerr, Anne, Sarah Cunningham-Burley, and Amanda Amos. 1998. The new genetics and health: Mobilizing lay expertise. Public Understanding of Science 7 (1): 41-60.

Lakoff, Andrew. 2017. Unprepared: Global health in a time of emergency. Oakland: University of California Press.

Latour, Bruno. 1987. Science in action: How to follow scientists and engineers through society. Cambridge: Harvard University Press.

Light, Donald. 1979. Uncertainty and control in professional training. Journal of Health and Social Behavior 20: 310-322.

McDonnell, Terence E., Christopher A. Bail, and Iddo Tavory. 2017. A Theory of resonance. Sociological Theory 35 (1): 1-14.

McGoey, Linsey. 2012. Strategic unknowns: Towards a sociology of ignorance. Economy and Society 41 (1): $1-16$.

Nelson, Alondra. 2011. Body and soul: The Black Panther party and the fight against medical discrimination. Minneapolis: University of Minnesota Press.

Petersen, Alan, Allegra Schermuly, and Alison Anderson. 2020. Feeling less alone online: patients' ambivalent engagements with digital media. Sociology of Health and Illness.

Poletti, Piero, Marcello Tirani, Danilo Cereda, Filippo Trentini, Giorgio Guzzetta, Giuliana Sabatino, Valentina Marziano, Ambra Castrofino, Francesca Grosso, Gabriele Del Castillo, Raffaella Piccarreta, ATS Lombardy COVID-19 Task Force, Aida Andreassi, Alessia Melegaro, Maria Gramegna, Marco Ajelli, and Stefano Merler. 2020. Probability of symptoms and critical disease after SARSCoV-2 infection. ArXiv [Preprint]

Pols, Jeannette. 2014. Knowing patients turning patient knowledge into science. Science, Technology and Human Values 39 (1): 73-97.

Prior, Lindsay. 2003. Belief, knowledge and expertise: The emergence of the lay expert in medical sociology. Sociology of Health and Illness 25 (3): 41-57.

Rabeharisoa, Vololona, and Michel Callon. 2004. Patients and scientists in French muscular dystrophy research. In States of knowledge: The co-production of science and the social order, ed. Sheila Jasanoff, 142. Abington: Routledge.

Radin, Patricia. 2006. "To me, it's my life": medical communication, trust, and activism in cyberspace. Social Science and Medicine (1982) 62 (3): 591-601.

Reich, Jennifer A. 2016. Calling the shots: Why parents reject vaccines. First edition. New York City: NYU Press.

Ross, Emily, Tineke Broer, Anne Kerr, and Sarah Cunningham-Burley. 2018. Identity, community and care in online accounts of hereditary colorectal cancer syndrome. New Genetics and Society 37 (2): 117-136.

Russell, Ginny, and Susan Kelly. 2011. Looking beyond risk: A study of lay epidemiology of childhood disorders. Health Risk \& Society 13 (2): 129-145.

Selinger, Evan, and John Mix. 2004. On interactional expertise: Pragmatic and ontological considerations. Phenomenology and the Cognitive Sciences 3: 145-163.

Tavory, Iddo, and Stefan Timmermans. 2014. Abductive analysis: Theorizing qualitative research. Chicago: University of Chicago Press.

Timmermans, Stefan, and Alison Angell. 2001. Evidence-based medicine, clinical uncertainty, and learning to doctor. Journal of Health and Social Behavior 42: 342-359. 
Vuolanto, Pia, Harley Bergroth, Johanna Nurmi, and Suvi Salmenniemi. 2020. Reconfiguring health knowledges? Contemporary modes of self-care as "everyday fringe medicine." Public Understanding of Science 29 (5): 508-523.

Wynne, Brian. 1996. May the sheep safely graze? A reflexive view of the expert-lay knowledge divide. In Risk, environment and modernity: Towards a new ecology, eds. Scott Lash, Bronislaw Szerszynski, and Brian Wynne, 44-83. London: Sage.

Publisher's Note Springer Nature remains neutral with regard to jurisdictional claims in published maps and institutional affiliations.

Larry Au is a Ph.D. Candidate in Sociology at Columbia University. His dissertation examines the uptake of precision medicine in China. His other research looks at the modernization of traditional Chinese medicine and the role of expertise in making sense of the Covid-19 pandemic.

Gil Eyal is Professor of Sociology at Columbia University, where he also co-directs the program on Precision Medicine and Society. He is the author, most recently, of The Crisis of Expertise (Polity 2019). 